\title{
Inhalt
}

Jörg REQUATE

Einleitung

I.

Konzeptionelle Fragen der Mediengesellschaft des 19. Jahrhunderts

Questions conceptuelles de la société des médias au XIX ${ }^{\mathrm{e}}$ siècle

Marie-Ève THÉRENTY

Les débuts de l'ère médiatique en France

Jörg REQUATE

Kennzeichen der deutschen Mediengesellschaft des 19. Jahrhunderts

Christian DELPORTE

La société médiatique du $\mathrm{XIX}^{\mathrm{e}}$ siècle vue du $\mathrm{XX}^{\mathrm{e}}$ siècle

II.

Presse als Medium gesellschaftlicher Selbstorganisation

Le rôle de la presse dans l'évolution sociétale

Thorsten GuDEwITZ

Die Nation vermitteln - Die Schillerfeiern von 1859 und die mediale

Konstituierung des nationalen Festraums

Alice PRIMI

La presse, un lieu de »citoyenneté« pour les femmes? (France et Allemagne, 1848-1870) 66

III.

Die alläglichen Sensationen - Le sensationnel au quotidien

\section{Anne-Claude AmBROISE-RENDU}

Les faits divers ou la naissance d'une instance médiatique de régulation du monde?

Philipp MÜLLER

»Éducateur« ou »mauvais garçon«?

Le capitaine de Köpenick et les bouleversements du paysage médiatique dans l'Allemagne de Guillaume II 
IV.

Skandalisierung - Scandalisation

Frank BösCH

Limites de »l'État autoritaire«. Médias, politique et scandales dans l'Empire ...

Martin KOHLRAUSCH

Medienskandale und Monarchie. Die Entwicklung der Massenpresse und die >große Politik im Kaiserreich

$$
\begin{gathered}
\text { V. } \\
\text { Visualisierung }- \text { Visualisation }
\end{gathered}
$$

Laurent BIHL

Les données législatives et les politiques de coercition de l'image entre 1881 et 1914

Daniela KNEISSL

Illustrierte Presse für den republikanischen Bauern: »Le Père Gérard.

Gazette nationale des communes« (1878-1887)

Ludwig VoGL-BIENEK

Projektionskunst und soziale Frage. Der Einsatz visueller Medien in der Armenfürsorge um 1900

Frank BECKER

Augen-Blicke der Größe. Das Panorama als nationaler Erlebnisraum nach dem Krieg von 1870/71

Personenregister

Medienregister 